\title{
A disposable one-piece left ventriculo-aortic bypass cannula
}

\author{
A. J. GUN N IN G \\ Nuffield Department of Surgery, Radcliffe Infirmary, Oxford
}

The diagnosis of traumatic rupture of the aorta below the subclavian artery is being made with increasing frequency. Although the majority of patients with this injury will die immediately, it has been estimated that 10 to $15 \%$ may reach hospital alive and survive long enough for surgical treatment to be undertaken.

Surgical treatment necessitates the clamping of the aorta above and below the rupture. Some form of bypass of the occluded aorta is mandatory to prevent ischaemic changes in the spinal cord and abdominal viscera. Until recently this has been achieved by inserting a cannula in the left atrium and, with the help of a pump, circulating part of the left atrial blood back through the femoral artery. This apparatus and a pump technician are not always available in most hospitals called upon to treat trauma. A simple method of achieving bypass would, therefore, be desirable. Molloy (1970), treating three cases of ruptured aorta, showed that left ventriculo-aortic bypass was a simple, quick, and efficient way of achieving aortic bypass.

Experience with the type of cannula used by Molloy (two cannulae with a connecting metal cannula and tap) showed this to be cumbersome

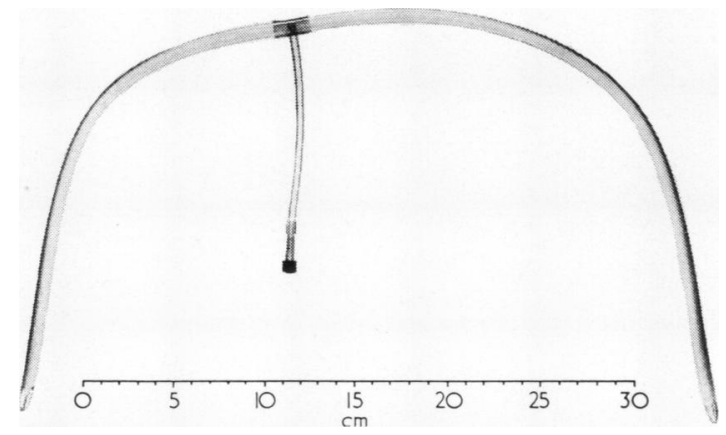

FIG. 1. Left ventriculo-aortic bypass cannula, $6 \mathrm{~mm}$ internal diameter, $8 \mathrm{~mm}$ external diameter, $70 \mathrm{~cm}$ long with side tube for venting air and/or recording pressures. and led to the development of the cannula (Fig. 1) shown in use in Figure 2. The cannula is prepacked, sterilized, and disposable and its main advantage is that it is in one piece and has a side arm with a female Luer fitting for aspirating air or recording pressures from the cannula.

The cannula can be made in any size. A $6 \mathrm{~mm}$ internal diameter cannula seems an adequate size, judged by Molloy's and our experience. Heparinization, potentially dangerous in patients with multiple injuries, is not necessary.

A patient in a regional hospital without heartlung bypass facilities has been successfully treated by the use of this cannula (Powley, 1971).

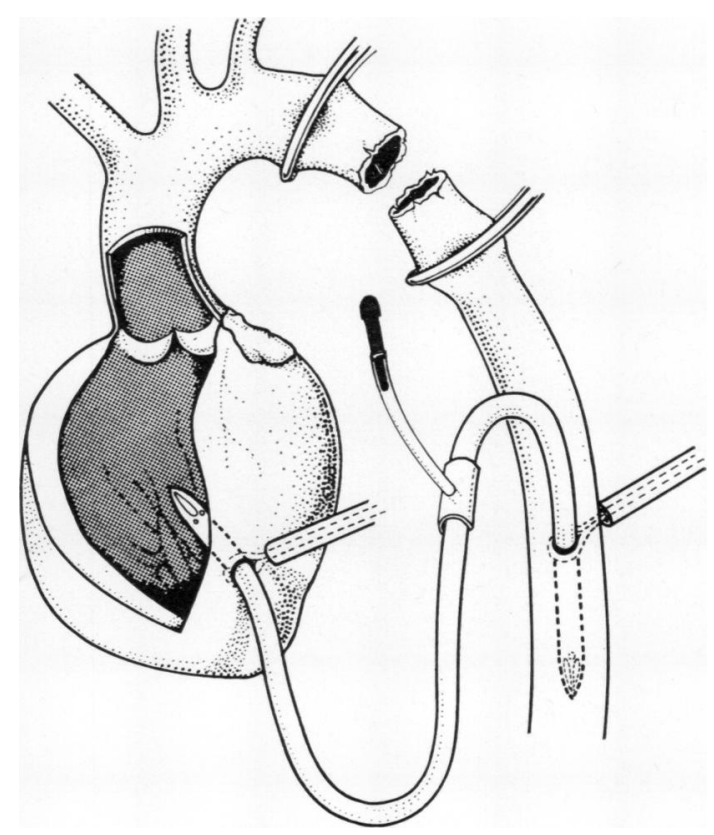

FIG. 2. The cannula in use. 
The cannulae are available from Polystan, Powley, P. H. (1971). Traumatic rupture of the aorta: Welbury Way, Hitchin, Herts.

My thanks are due to Miss S. Barker and Mr. D. R. Floyd of the Medical Illustration Department, Radcliffe Infirmary, Oxford.

\section{REFERENCES}

Molloy, P. J. (1970). Repair of the ruptured thoracic aorta using left ventriculo-aortic support. Thorax, 25, 213. repair using ventriculo-aortic bypass. Proc. roy. Soc. Med., 64, 1085.

\section{AdDENDUM}

Since this paper was written two further cases have been successfully treated using this catheter: (1) a traumatic rupture of the aorta; (2) a large syphilitic aneurysm of the descending aorta. 